\title{
The Importance of the Preceptor-Preceptee Relationship in Creating Well Prepared Professionals: A Make or Break Experience
}

\author{
Tagwa Yusuf Omer ${ }^{1} \&$ Shehnaaz Mohamed Moola ${ }^{2}$ \\ ${ }^{1}$ King Saud bin Abdulaziz University for Health Sciences-Jeddah, Kingdom of Saudi Arabia \\ ${ }^{2}$ Department of Nursing Science, School of Healthcare Sciences, Faculty of Health Sciences, University of \\ Pretoria, Arcadia, South Africa \\ Correspondence: Shehnaaz Mohamed Moola, Department of Nursing Science, School of Healthcare Sciences, \\ Faculty of Health Sciences, University of Pretoria, Private Bag X323, Arcadia 0008, South Africa.
}

Received: June 10, 2018 Accepted: November 27, 2018 Online Published: December 13, 2018

doi:10.5539/gjhs.v11n1p1 URL: https://doi.org/10.5539/gjhs.v11n1p1

\begin{abstract}
Objectives: In this study, we explore the 'make or break' challenges faced in the preceptor-preceptee relationship. The preceptor-preceptee relationship needs to evolve from a teacher-student dynamic to a collegial partnership.
\end{abstract}

Methods: This qualitative study used focus group interviews which explored challenges experienced by preceptors and preceptees. The preceptors included ten clinical teaching assistants and 14 clinical professionals. The preceptees included ten student nurses. In total, we interviewed 34 participants. The interviews were audio recorded, transcribed verbatim and thematically analyzed.

Results: Both preceptors and preceptees experienced challenges in developing healthy relationships. Preceptors felt that they were committed and trained to teach, and that fulfilling an extended role was beyond their reach. Preceptees had difficulty realizing nursing practice and transitioning from a student to a professional role. Both parties identified strategies for developing healthy professional relationships. Preceptors could extend their professional role to include a mentorship facet. Preceptees could be exposed to diverse clinical environments with guided transitioning to facilitate the change from student to professional.

Conclusion: Student nurses need a caring environment to transition from a student role to a professional role. The relationship based care model undoubtedly influences the teaching and learning process by fostering a caring attitude and commitment to teaching and learning. Preceptees develop a sense of belonging and are motivated to accept and adapt to practical realities.

Keywords: preceptor, preceptee, relationship, student nurse, clinical professionals, clinical teaching assistants

\section{Introduction}

Most health and educational programs depend on preceptors to facilitate the transition of the preceptee from student to professional nurse. Although experience and proficiency are important, the preceptorship relationship has a considerable caring component. The relationship between preceptor and preceptee symbolizes caring expressed in humane actions and words. A caring and supportive preceptor workforce may help to transition student nurses into professionals by enhancing students' sense of belonging in the nursing profession.

Preceptorship is defined as a 'teaching-learning' model where an experienced preceptor guides an inexperienced preceptee through their practical training (Moyet \& Wittmann-Price, 2008; deWolfe et al., 2010; Park et al., 2011). Student nurses or preceptees are in the process of learning the 'culture or way' and internalizing group norms and professional values as they develop in the nursing profession (Wilkens, 2003). Students acquire knowledge, skills, competence, confidence, values, ethics and a multitude of attributes to transition into the role of professional nurse. The transition process also has a socialization component, which occurs through observation and role-modeling behavior within the learning environment (Lai \& Lim, 2012). While few studies have explored the relationship between preceptors and preceptees in the nursing profession, many have explored unsuccessful transition from student to professional nurse, which is often accompanied by low productivity, low morale, lack of job satisfaction, increased absenteeism, increased errors and near misses, burnout syndrome and finally an end to a nursing career. Effective preceptorship programs have reduced turnover by $186.102 \%$ in a six month period and led to neophyte nurses making almost no medication errors (Lee et al., 2009). 
Preceptor relationships are fluid, and can assume a collaborative, integrative, team approach, or take on the form of a one to one relationship. Although one-to-one relationships have resulted in positive experiences, leading to expanded knowledge, skills acquisition and theory-practice integration, several aspects on the dynamics of one to one preceptor relationships need to be explored. These aspects include understanding how the culture of support and challenges experienced affect commitment to the preceptorship relationship. The commitment of the preceptor may affect the sense of belonging of the student, who may expect different outcomes from the preceptorship relationship. A lack of professional comportment may also negatively affect the transition from student to professional. The preceptor role has to adapt to diverse learning needs, the complex health environment and needs to recognize that ongoing support is crucial to a preceptorship relationship. Students feel a need to belong and to be seen as part of a nursing community (Andrew et al., 2009). Nurse preceptors facilitate students towards becoming a part of the professional team (Sedgwick \& Yonge, 2008). A positive preceptorship relationship is a crucial step in exploring and discovering the professional role (Bremmer \& O'Brian, 2007). For student nurses, preceptorships facilitate a structured process of internalizing soft skills, practical skills, theory, ethics, values and professional comportment in transitioning from student to well adapted nurse practitioner.

In the nursing profession, preceptorship relationships are intricately tied in with patient care. According to Kolouritis (2004) the relationship-based care model aims to protect the patient as well as those providing the care through mindfulness and understanding of emotional responses of the 'self' in order to connect with professional others, the patient and family. Caring brings us to our basic purpose, namely, caring for and connecting with other human beings. In the nursing profession, the teaching and learning environment should foster caring and healing. A well supported nurse from a caring environment will be better prepared to render quality patient care in a changing clinical environment (Koloroutis, 2004).

In this study, we consider the caring aspect of the preceptorship relationship and explore the perceptions of both preceptors and preceptees regarding possible barriers and facilitators of a successful preceptorship relationship. We used the relationship-based care model of Kolouritis, (2004) as a conceptual framework to clarify our findings.

\section{Methods}

We explored the lived experiences of preceptors and preceptees using a qualitative approach. Focus group interviews explore real life situations and interactions of people, revealing attitudes, feelings, a range of experiences, values and views. Information may be disclosed more effectively during focus group interviews and enhance interaction (Krueger, 1994). We purposively sampled participants, who included nursing students, clinical teaching assistances and clinical preceptors.

\subsection{Setting}

The study was conducted in a nursing college in Saudi Arabia affiliated to a 900 bed teaching hospital, where clinical training takes place.

\subsection{Participants}

The sample included ten student nurses who are in their undergraduate Baccalaureate program and ten registered nurses who are referred to as clinical teaching assistants, as well as fourteen clinical preceptors from the clinical areas of the hospital, who hold a Baccalaureate degree in nursing.

\subsection{Data Collection}

We conducted three focus group interviews (Krueger, 1994), one with student nurses, one with clinical teaching assistants and one with the clinical preceptors. The focus group sessions were arranged to ensure confidentiality and privacy. Researchers facilitated the focus group interviews, which were moderated by co-facilitators. Each focus group interview was held at one of two designated locations, either the hospital or the nursing college. Participants were informed about the study and asked to sign informed consent if they agreed to participate. Participants were able to withdraw from the study at any point. In appreciation of their time, knowledge and experiences shared, participants were indulged in a refresher at the start and a light lunch after concluding. Table 1 explains how the researchers' maintained trustworthiness.

The focus group interviews were semi-structured. The researchers asked a key question at the start of the interviews, which stimulated further discussion. The researchers ask the preceptors, "How do you provide a suitable learning environment whilst students are in the process of becoming professional nurses?" The researchers asked the students, "How are you provided with a suitable clinical learning environment while you are in the process of becoming a professional nurse?"

The study was approved by the ethics committee of the associated university and hospital review boards for IRB 
approval and consent to conduct the study.

Table 1. Measures for ensuring trustworthiness

\begin{tabular}{|c|c|c|}
\hline Strategy & Criteria & Applicability \\
\hline Credibility & $\begin{array}{l}\text { Prolonged } \\
\text { engagement }\end{array}$ & The researchers interacted and worked closely with the participants from 2013. \\
\hline \multirow[t]{5}{*}{ Triangulation } & $\begin{array}{l}\text { Multiple } \\
\text { investigators }\end{array}$ & $\begin{array}{l}\text { The researchers used independent researchers, a facilitator and a joint facilitator } \\
\text { from the initial planning phase to the final report. A co-analyst confirmed } \\
\text { findings using the computer software, NUDIST 4-0. }\end{array}$ \\
\hline & Multiple sources & Focus group interviews, field notes and audio-recordings were used. \\
\hline & Member checks & $\begin{array}{l}\text { Participants validated information as their own, from verbatim quotes and } \\
\text { in-field notes and further supported by a literature review. }\end{array}$ \\
\hline & Peer examination & The study was discussed with peer researchers. \\
\hline & $\begin{array}{l}\text { Authority of the } \\
\text { researchers }\end{array}$ & $\begin{array}{l}\text { The researchers have conducted qualitative methods during their PhD studies } \\
\text { and are experienced in qualitative research. Attend workshops frequently. }\end{array}$ \\
\hline \multirow[t]{3}{*}{$\begin{array}{l}\text { Applicability and } \\
\text { Transferability }\end{array}$} & Sample & $\begin{array}{l}\text { A purposive sampling method was used. } \\
\text { The findings of this study can be applied to other populations groups, cultures } \\
\text { and religions. }\end{array}$ \\
\hline & Peer evaluation & $\begin{array}{l}\text { Peer checking by colleagues and supervised by experts. } \\
\text { Independent checking by colleagues and supervised by experts. }\end{array}$ \\
\hline & $\begin{array}{l}\text { Code-recode } \\
\text { procedure }\end{array}$ & $\begin{array}{l}\text { Consensus discussion between the researchers and the independent coder. The } \\
\text { researchers used the raw data from the focus group interviews with students } \\
\text { (preceptees) and preceptors. }\end{array}$ \\
\hline Neutrality & Bracketing & $\begin{array}{l}\text { The researchers recognized their own biases and intentions, which were } \\
\text { bracketed during the interviews. }\end{array}$ \\
\hline $\begin{array}{l}\text { Consistency and } \\
\text { dependability }\end{array}$ & Audit trail & Verbatim quotes were checked by listening to the audio-taped recordings. \\
\hline Confirming the data & Audit trail & $\begin{array}{l}\text { The researchers used the raw data from the focus group interviews with students } \\
\text { (preceptees) and preceptors. } \\
\text { Data analyses and conclusions were formulated. }\end{array}$ \\
\hline
\end{tabular}

Guba and Lincoln (1985: 306) and Hallet, 1995; Taylor, 1995 and Beech, 1999.

\subsection{Data Analysis}

All the focus group interviews were recorded on at least two audio cassette recorders, in the event of a technical error. The researchers used tapes of 90 minute duration. References to gesturing or remarks made were indicated in field notes. Audio-tapes were transcribed verbatim. The researchers listened to the audio-tapes repeatedly to ensure that data saturation was reached (Krueger, 1994). Researchers read transcripts and field notes independently. Transcripts were analyzed and open coded into key themes, further analyzed into sub-themes until no new themes emerged. Table 2 gives an overview of the themes and sub-themes. 
Table 2. Important themes and sub-themes that emerged from focus group interviews exploring the preceptorship relationship

\begin{tabular}{ll}
\hline Theme & Sub-theme \\
\hline 1. Being committed and trained for the preceptor role & 1.1 diversity in transitioning \\
& 1.2 the preceptor eases the transition \\
2. The student realizes nursing practice & 2.1 the student gives meaning to the clinical practice \\
3. The student integrates a student role into a professional role & 3.1 the student internalizes norms, values, culture and ethics \\
& 4.1 role model \\
& 4.2 educator role \\
& 4.3 facilitator role \\
4. The extended roles of the preceptor & 4.4 protector role \\
& 4.5. socialization role \\
& 4.6. motivator role
\end{tabular}

\section{Results}

\subsection{Demographic Characteristics}

Preceptees (student nurses, SN) were female and on average 23 (20-25) years old. Preceptors included clinical teaching assistants working at the nursing college. The clinical teaching assistants (CTAs) were all female and on average 35 (40-58) years old. Clinical preceptors from the health service (hospital staff, HS) were female and on average age of 35 (30-47) years old. The mean experience of precepting was in range of $0-6$ years.

\subsection{Theme 1 Being Committed and Trained for the Preceptor Role}

Preceptors felt that an effective preceptorship relationship depended on the "commitment and training of the preceptor' (CTA3) and that preceptors not committed to the role experienced problems with students. Clinical teaching assistants described the characteristics and qualities needed to be a preceptor using the following words, 'the heart to teach', 'compassion and passion' (CTA3) 'committed' (CTA 10) 'manage people in difficult situations is important' (CTA5), 'everyone must be seen as an individual (CTA 9, 7, 10). Hospital staff $(2,1,14,12)$ mentioned the need to be 'flexible', 'intellectually strong', 'experienced', 'skilled', 'dedicated, 'approachable' (HS5), 'deal with differences in people' (HS4), 'patient' (HS11) and 'knowledgeable' (HS7). Hospital staff stated the following, 'that if you don't have the heart of being a preceptor, even if you teach and are knowledgeable' (HS $9,10)$.

The literature supports that commitment to the preceptor role is enhanced by interested students (Monareng et al., 2009), positive self-awareness, self-confidence, having a mature age, experience and being formally trained as a preceptor (Hallin \& Danielson, 2009). Preceptors who receive training are more willing, committed, and capable of mentoring student nurses (Donley et al., 2014).

Sub-theme 1.1 Diversity in transitioning

Student nurses shared that language and cultural barriers that made it difficult to follow preceptors. In a preceptorship relationships 'one has to deal with differences in people' (SN4). Students found that preceptors of the same culture were more empathetic, 'who guides, teaches and recognizes weaknesses, she's polite, they trust us more' (SN7). Similarly 'the language between the student and preceptor should be the same' (SN 2, 9, 5), or 'they (SNs) should be given a course in Arabic' (SN 10, HS 6). Most clinical preceptors mentioned that they had to accommodate other cultures (HS 2, 6, 8, 12).

Differences in cultural and educational backgrounds are possible stressors in the teaching/learning environment that may make or break a professional relationship. Individuals are unique beings and should be treated respectfully (Johnstone \& Mohide, 2009). A preceptor may require the assistance of faculty or an interpreter for students whose first language is not English (San Miguel et al., 2006).

Sub-theme 1.2 The preceptor eases transition

Student nurses mentioned that they were dependent on preceptors for their guidance in easing transition to a professional role. According to the preceptees, their preceptors were their 'medium for understanding the culture of nursing in the clinic' (SN 1, 2, 5). According to the CTAs 'it is very important for us to be around, because they are following our footsteps' (CTA 1, 4, 2, 5, 6) and 'that a role model means what you teach, you should know 
especially personality wise, like this simple thing as 'dress code' the students sees how you move, how you talk how you greet, how you consider the team in nursing and the role of professional nurse nursing practice' (CTA 7). In contrast, hospital staff had little time for dealing with students due to lack of 'support from the higher management' (HS1), lack of 'financial support' (HS1), lack of 'support from colleagues' (HS7), 'time constraints (HS6), heavy 'work load' (HS 11), lack of 'open communications' (HS 12) and 'refusal to do unrelated work' (HS 13).

Students were adversely affected by the attitude of preceptors and were unable to learn in a hostile environment. Some preceptors had outbursts in front of patients and emphasized that 'shouting' (SN 5) makes them feel 'nervous, frustrated and confused' (SN 7) and 'she (HS) behaves 'aggressively' when procedures are not done competently' (SN 4, 5). Student nurses felt that HS must learn to 'control her mood' (SN 3), 'not humiliate, but respect others' (SN 6). One SN mentioned 'I feel like I have 'committed a crime' (SN 2). Student nurses had a need for more advanced training in the clinical setting, rather than 'from scratch' (SN 5) and as preceptors 'they (HS) should not be teaching the basics, but show them the routine, 'experience, work preparation' (SN 7), 'support from colleague' (NS 5), 'dedication skills' (SN 10), 'knowledge, commitment' (SN 7), 'time management, good interrelationship' (SN 5, 10, 7).

(Horton et al., 2012) supports that if preceptees are expected to be able to practice caring, then they must be shown caring within the preceptor-preceptee relationship. Clinical preceptors need to have a lower patient workload to be effective in the role (Horton, 2012). Precepting can cause significant stress and preceptors are advised to reflect on their immediate actions, to highlight educational experience and clinical decision making in developing themselves professionally for future situations (Fidelindo et al., 2016).

\subsection{Theme 2. Realizes Nursing Practice}

The second theme concerned the feelings of SNs experiencing the clinical environment for the first time, which were mainly feelings of overwhelm. Educational objectives for SNs were not perceived as realistic to practice realities. The CTAs mentioned that the clinical environment is an 'anonymous, mysterious world for the girls' (CTA3); 'a different world' (CTA 7), 'it is not only giving medication to your patient, since we are nurses we deal with human beings, not only their physical illnesses, but also their emotional' (CTA 4, 10). When dealing with patients, 'it is not only the knowledge, the skills' (CTA 8) 'but it is how you try to understand or treat your patient as a human being' (CTA 9). Furthermore, human beings are holistic beings (CTA 2, 5). Hospital staff were also concerned with 'time management' and 'interpersonal relationships' (HS 7).

Preceptees felt that preceptors were unable to communicate professionally and caused more distress being unsupportive and uncaring. 'Students need guidance in training, does not require humiliating... it is more than critiquing.... and evaluation of performance' (HS 4), another stated that when 'I am questioned I am made to feel like a criminal, because I don't know something' (HS 8).

Students coming to practice experience a gap between what they have in their minds and what is experienced in reality (Dimitriadou et al., 2013). Theory and practice within realistic expectations reduces the 'reality of shock' when students enter the practice environment for the first time (Duteau, 2012). A caring student-preceptor relationship enhances a caring and safe environment (Hilli et al., 2014).

Sub theme 2.1 The students give meaning to the clinical environment

Student nurses give meaning to the clinical environment and explored uncomfortable feelings. The verbatim quotes revealed how distressed and uncomfortable SNs felt interacting with patients in the real life setting. The feelings of SNs are described as the 'first time in the 'reality of the clinical environment' (SN 3), 'first time to deal with patients and to do a job' (SN 5). They 'felt discomfort and fears' (SN 8), 'horrible for me' (SN 3) 'it was the first time experience' (SN 4), 'the environment was not comfortable for me' (SN 2), 'it was a strange place' (SN 7 , 1). A few responders nodded approval.

Students perceive the practical environment whilst "learning the ropes" (Messersmith, 2008). Students entering the practice environment need to learn their professional role. Students need to adapt to inter-professional pressures, conforming to the behaviors and expectations of the professional role (Dimitriadou, 2013). Preceptors who are overloaded and lack time cannot fulfill student needs and challenges (Broadbent et al., 2014). Preceptors who are overly critical, unsupportive and lacked commitment, are not perceived as role models (O'Mara et al., 2014). Socialization of students in the practice environment enhances feelings of belonging, confidence and trust (Carlson, 2013). 


\subsection{Theme 3 the Student Role Is Integrated Into a Professional Role}

Some students perceived transitioning from student to professional as overwhelming but others found the experience less intimidating. Some students emphasized that they must be 'perceived as students' (SN 4, 5), 'I want to be seen as a student and not as a professional' (SN 10), 'from the first day, we should learn and they should teach' (SN 6). Some students reflected positively 'it puts responsibility on us, but I did not feel it was horrible, I feel it was very interesting' (SN 7), 'teach, give guidance and training' (SN 9). Students emphasized that 'the teaching style should focus on teaching/training mostly', it is more than critiquing, 'but evaluation of performance'.

When moving from theory to clinical practice; clear, realistic learning objectives need to be stated (Charleston \& Happell, 2005). New knowledge, facts and skills, values and norms are internalized through interaction with others (Shiyanski et al., 2006). Students need to be proactive rather than reactive or passive learners (DinMohammadi et al., 2013; Price, 2009). A positive experience with an experienced preceptor is a crucial step in assuming the professional role (McIntosh cited in Price, 2008). For students, preceptors who are mostly concerned with competencies are perceived as uncaring and harsh and do not reflect their ideal role models (Mcintosh cited in Price, 2008). Nursing practice is a practical wisdom, which is fostered by being sensitive and human in the preceptor-preceptee relationship (Myrick et al., 2012).

Sub-theme 3.1 The student internalizes norms, values, culture and ethics.

In the nursing college, student nurses internalize the culture of nursing, values, norms and ethics. Clinical preceptors felt that 'students must have the willingness to learn' simple objectives, compare with policy and system in the hospital' (HS 4, 9, 10,13), 'compares the learning objectives of what was attained at the end of the day' (HS 2, 5, 10), 'teaching a person your routine is not hard but are they willing to learn or how eager are they to learn is the question' (HS 2). The clinical teaching assistants stated that 'I involve them, with endorsements and identify if learning objectives have been met' (CTA 8), ensure that 'feedback is given on time' (CTA 8), 'orient our students, orientation is very important based on the course syllabus or on the course outline or objectives and ethical code' (CTA 6). Clinical teaching assistants also highlighted 'the art of motivating', 'I think for me it is the art of motivating the students, because if you don't have the art of motivating then I don't think you will have a successful outcome' (CTA 7, 9).

Students struggled to internalize their professional role and stated 'we are not professional yet, and are in the working environment for the first time' (SN 1,2,6) and 'being in the hospital for the first time is a scary experience' (SN 4).

Information is internalized when observing role models or mentors in their professional capacity (Shiyanski et al., 2006). Students are inducted into the culture of nursing, establishing social roles in a social structure through interaction with others (Shinyaski et al., 2006). Nurses have a distinct body of knowledge, a responsibility to society by an ethical code of standards to uphold (ANA, 2010b). Nurses are socialized into nursing by learning how to relate to patients and are in the process of developing a professional identity (Price, 2009). Whilst developing a professional identity, student nurses need a culture of safety during all phases of learning. In the nursing profession, students do better when they care and have an interest in nursing without being induced to learn (Kristan Ho \& Reed, 2013), this caring is further developed if student nurses feel cared for and appreciated.

\subsection{Theme 4 The Extended Roles and Responsibilities of the Preceptor}

Sub-theme 4.1 Role model

Student nurses are socialized easily when they perceive preceptors as role models. They copy professional comportment, and strive for competence. Not perceiving the preceptor as a role model may obstruct a successful relationship. In this study, the preceptors knew the qualities of a good role model, but the preceptees did not perceive these qualities in their existing relationships. Clinical preceptors expressed that a role model means what you teach and demonstrate, including 'clinical competence' gives 'feedback', be a 'good role model'(HS 3, 4, 8, 12) and model professional behavior (HS 1,2). The CTAs mentioned that they should have 'effective communication skills' (CTA 2), learn to 'control her mood' (CTA 13) and 'but respect others' (CTA 14). Students found these qualities lacking and had negative experiences, 'feel 'nervous, frustrated and confused' and makes 'facial expressions', behaves 'aggressively' when procedures are not done competently (SN 6, 8, 9).

Nurses are socialized into their professional roles in two phases, firstly through education and training and, secondly through agents in the work environment who influence, guide, support, protect and nurture (Shiyanski et al., 2006). Student nurses are continuously internalizing information and behavior by careful listening and observing role models/mentors and role modeling professional behavior themselves (Shiyanski et al., 2006). 
Sub-theme 4.2 Protector role

A culture of safety is important for quality practice and, students should internalize and exercise safety during all phases of learning. Healthcare workers need to exercise transparency for a safe environment. Quality and safety should be ensured by CTAs and HS. Student nurses depend on the CTS and the HS for guidance, for example NS 2 is assigned a patient and 'competence is assessed' (NS 2,10) and agreed that 'the CTA adds to my information' (NS 10, 2, 4), and 'they give us objectives and the time to ask questions' (NS 3, 4). Clinical preceptors are responsible for giving constructive feedback, modelling capability and clinical judgment by assigning the most appropriate patient to the student for effective learning' (HS 1, 3). One CTA expressed 'so you need to have outcomes, so you also have to assess your students, how the students have come up with competency skill' (CTA $8)$.

The preceptor protects the preceptee and the patient and, facilitates a rich learning non-human practical environment ensured by safe, competent, practice (AACN, 2008). Safe practice is the focus on social competence in academic and practical environments (Sedgwick \& Harris, 2012). Preceptors who are supported and instill a sense of importance to the role are better able to transition student nurses into the clinical environment effectively (Happel, 2009). Patients are better informed and expect professional, safe, competent and satisfied nurse practitioners to care for them.

\section{Sub-theme 4.3 Educator role}

The educator aims to narrow the gap between theory and practice. To maintain an effective learning environment, preceptors need to use their time to apply learning objectives to feel committed in the role, without feeling overloaded. Students agreed that 'the clinical preceptor adds to my information', she provides opportunity for 'learning, guides, teaches and recognizes weaknesses' (SN 4, 1, 5, 6), 'she (CTA and HS) accommodates me, teaches me and asks me to follow her' (SN 2), and 'even though she is overloaded with her own work she accommodates me' (SN 6, 10). As educators, CTAs stated 'so you need to have outcomes, so you also have to assess your students' (CTA 1) and felt 'that if your student can't get you...for example, you are using terms which can't be understood by students' (CTA 4, 6) and 'the ideal preceptor is the level of understanding of the student should also be considered' (CTA 10). Hospital staff felt that the 'hospital is a good learning experience and the hardships encountered' (HS 12), 'students must have the willingness to learn' (HS 14), nursing is continuous learning process and through teaching you are also learning (HS 9). Preceptors also valued the opportunity 'increase your knowledge through explaining to that person the process and procedures' (HS 6).

Preceptors face challenges, including overload (Hurley \& Snowden, 2008), lack of support, inadequate preparation of the preceptor role, barriers in communication with faculty and being held accountable for student success or failures. Theory to practice inconsistencies of students leads to perceived lack of knowledge and unhealthy preceptor-preceptee relationships (Matua, 2014)

Sub-theme 4.4 Facilitator role

Preceptors have to facilitate the transitioning of student nurses to professional nurse. According to CTAs, they have to 'involves them (SNs), with endorsements and identify if learning objectives have been met' (CTA 8) and ensure that 'feedback is given on time' (CTA 8), to help them become professional. The clinical preceptors have to 'follow policy and procedure' (HS 4), 'students must have the willingness to learn' (HS 12), 'give guidance and training' (HS 12).

The student should adopt an independent role while being facilitated and guided (Franklin et al., 2014). Matua et al. (2014) indicated that treating students as colleagues created a harmonious relationship of mutual respect, open communication and trust.

Sub-theme 4.5 Socialization role

Students are socialized into the clinical environment and are introduced to the professional team during the orientation period. Student nurses described 'In the first day we establish a rapport not only with students but with Nurse' (SN 3), 'collaborative learning with other nurses, managers or supervisors and communicate with them' (SN 7), 'how you consider the team in nursing and the role of professional nurse nursing practice' (SN 10).

Sedgwick, Yonge (2008) showed that nurse preceptors assist students to become members of the team. Students feel they want to belong and to be seen as part of a nursing community (Andrew et al., 2009). Student nurses who are exposed to collaborative relations are better prepared and confident individuals who will adapt to the realities of the clinical practice. Preceptors who are supported and instill a sense of importance to the role are better able to cope with student nurses. 
Sub-theme 4.6 The Evaluator role

Preceptors need to evaluate students and provide prompt feedback. Students need to self-evaluate by reflecting on the task at hand. According to the CTA 1 'So you need to have outcomes, so you also have to assess how the students have come up with competency skills'. Evaluation is also important for students, 'she asks me to do a task and checks on my competency' (SN 6). In the hospital, clinical preceptors need to 'confirms, critiques, modifies and adds to knowledge' (HS 12), 'gives feedback (HS 14), timeously' (HS 4). Evaluators also need to 'simplify the objective, compare with the policy or system involve' (HS 9), 'give assignments' (SN 10), 'make them (SNs) involve' (HS 11) and 'set base line expectation' (HS 8).

Helminem et al., (2014) emphasized that preceptors must be skilled in assessing student nurses. Constructive critique is aimed at encouraging students to improve their competencies and cognitive abilities (Omer et al., 2015). The student should be cognizant of deficits, able to reflects and improve and progress towards becoming a professional (McIntosh, 2003).

Sub-theme 4.7 The motivator role

The concept the 'art of motivating' emerged from the content when CTA's stated, 'I think for me it is the art of motivating the students.... because if you don't have the art of motivating than I don't think you will have a successful outcome' (CTS 7, 9)."

Unmotivated students' may negatively influence other students. Because caring is an intrinsic motivator, nurses may transition into their professional role quite easily, without being coerced. Unmotivated students need to be extrinsically motivated, encouraged and guided (Kristan et al., 2013).

\section{Discussion}

In this study, we identified challenges and strategies to encourage and enhance relationship building between preceptors and preceptees. We discuss our findings using a conceptual framework, the Relationship Based Care model of Koloroutis (2004), adapted for this study in Figure 1. Linking various roles and relationships between the preceptor and the preceptee.Mutual respect is imperative and confidence and trust is enhanced when learning outcomes have been achieved. Preceptors have multiple roles, all of which are enhanced when there is a caring relationship between the preceptor and preceptee. 


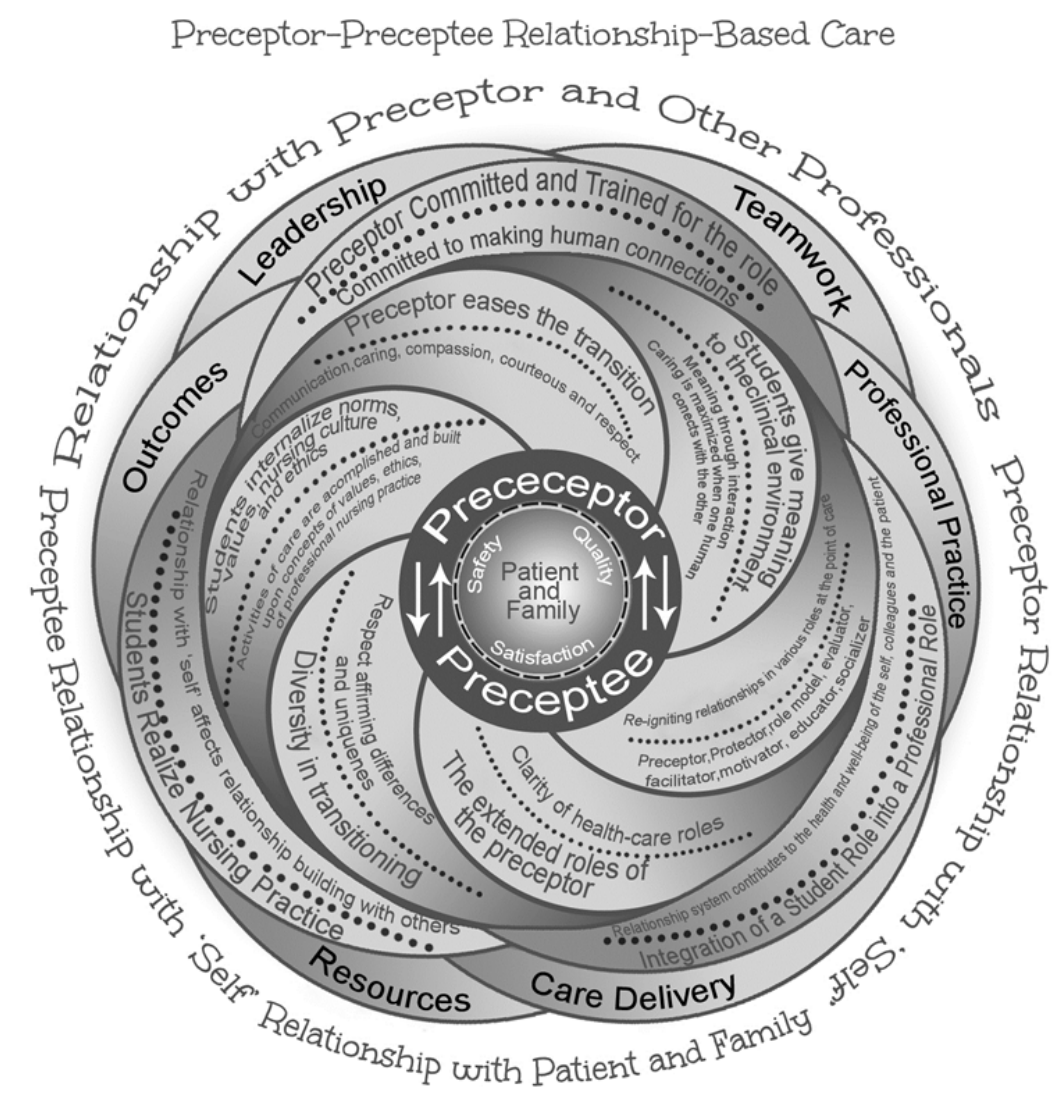

Adapted from Koloroutis, M (2004). Relationship Based Care. A Model for Transforming Practice

Figure 1. A conceptual framework of (Kolouriris, 2004), is adapted for this study, linking various roles and relationships between the preceptor and the preceptee

The RBC model of Koloroutis (2004) considers three relationships, namely establishing a therapeutic relationship between patients, co-workers and self. There are six essential dimensions that interact, namely, teamwork, leadership, professional nursing practice, care delivery, resource driven care and outcome measures. The clinical experience of students is determined by the physical environment and patient care needs. We adapt the RBC model and assume that nursing students (preceptees) are inspired when teaching and learning is displayed by professional roles integrated within caring relationships. Universities are responsible for the cognitive and theoretical application of RBC on simulated patients while clinical practice provides a 'live' experience on 'real' patients (Happell, 2009). In our study, preceptors and preceptees face challenges, centered around human connections in a 'make or break; relationship. Preceptors identified that commitment and preparation for the role were a challenge. Interpersonal relationships and teamwork are based on deep commitment and caring attitudes and behaviors, rather than compliance in the role. Preceptors who are trained are able to skillfully connect with preceptees. The student gives meaning through interaction and relationship building.

Another challenge that affected interpersonal relationships was the effect of diversity on transitioning. In a RBC, cultural relationships are enhanced when there is respect in affirming differences and uniqueness. The shortage of staff worldwide leads to students being educated by diverse cultures and religions. Preceptors should ease the transition from student nurse to a professional role. Preceptors should strive towards being culturally competent and sensitive. The preceptorship relationship is also affected by the experiences of student nurses as they realize nursing practice. According to the RBC model, the patient and family should be the central focus (Koloroutis, 2004), and preceptors and preceptees are responsible for patient care. All activities and relationships should result in safe patient care and family satisfaction. Caring relationships between preceptors, preceptees and patients can be limited if students are overwhelmed by the realities of the clinical environment, or if they are unsupported. Professional preceptorships and caring patient relationship can be fostered by engaging in open communication on expectations, responding to adversities, prompt feedback, validating, reassuring and being respectful. Respect and 
courtesy are essential components of the RBC model, where the relationship with 'self' affects relationship building with others (Koloroutis, 2004)

In the nursing profession, student nurses have to transition to nursing professional. The process is daunting for young, inexperienced student nurses who have never had to deal with the realities of clinical practice. The formation of knowledgeable, competent and caring student nurses into well prepared professional nurses is a shared responsibility, in which the student internalizes norms, values, culture and ethics. Implementing a RBC model of care provides a collective belief in defining caring attitudes towards the delivery of care, professional development and in an ongoing improvement of the patient, nurse and organizational outcomes (Koloroutis, 2004).

In the preceptorship relationship, preceptors have to fulfill extended roles. Organizations should be responsible for the skills development and training of preceptors. The RBC model of Koloroutis (2004) implements role clarity and work alignment as a process which enhances the clarity of health care worker roles, professional practice, teamwork and delegation of tasks. The outcomes are based on the alignment of patient-centered care using the most skilled health care worker, with the best possible resources. In extending the preceptor role to a protector, role model, evaluator, facilitator, motivator, educator and socializer, both the preceptee and the patient form the foundation of the precepting role. Teaching by example as a role model educates by being supportive and motivates by demonstrating commitment. Students seek preceptors who are committed in the role, who give regular feedback and reflect on practice as a dual process of care and education. This allows the preceptee to give meaning to the clinical environment and even if the preceptee is overwhelmed by clinical realities, support from the preceptor and inter-professionals will facilitate the student into a professional role. The success of a professional relationship must reflect realistic expectations of the clinical environment and in which Happell, (2009) viewed preceptorship as an essential element of high quality nursing education. This inevitably leads to high quality patient care established through an interactive process of professional relationships. Nursing education and the clinical practice environment cannot be viewed in isolation and merging these recognized the importance of the preceptorship relationship in nursing education. A conceptual framework of (Kolouriris, 2004) in Figure 1, is adapted for this study, linking various roles and relationships between the preceptor and the preceptee.

\subsection{Limitations}

The responses gathered from the focus groups were from one health and academic organization and thus may not be representative of other organizations. The focus group size ideally stipulates 6-10 respondents (Beech, 1999, p. 56) but in this study it extended to 14 clinical preceptors from the health facility, which might have influenced the findings. The intricacies of the collective perceptions have illuminated 4 themes, which could be differently perceived in another study. Preceptors of diverse cultures could have influenced the findings. Students perceived Saudi preceptors as more caring and accommodating. It is worthwhile to mention that the authors do not suggest that 'caring' and a 'sense of belonging' are the most significant concepts in relationship building, but that there are many factors, or hidden in the curriculum. However despite these limitations the authors are of the view that the results of this study offers a significant awareness and comprehension of a 'make or break' preceptor-preceptee relationship.

\section{Conclusions}

Through real lived experiences, rich, meaningful perceptions emerged when preceptors and student nurses explored the efficacy of teaching and learning in the process of building a relationship. We identified four significant themes, namely commitment in the preceptor role, the students realizes nursing practice, the student integrates a student role into a professional role and the extended roles of the preceptor. Highlighting a caring environment in the process of teaching and learning is significant for the sustainability of the relationship based care model between preceptor and preceptee in nursing education. The relationship based care model undoubtedly influences the teaching and learning process in preceptorship, and ultimately had implications for patient care. The findings of this study can be used in the preparation of preceptors and preceptees to display caring, commitment to teaching and learning and motivate students' in accepting and adapting to practical realities and applying congruent theory to practice learning objectives. The relationship-based care model supports the importance of the acquisition of knowledge and skills in a 'caring' collaborative learning environment.

\section{Acknowledgements}

The authors sincerely thank Professor Wafika, Thaher, Suliman for her valuable support. The authors are also grateful to the preceptors and preceptees for sharing their views and experiences. 


\section{Competing Interests Statement}

The authors declare no conflicts of interest that may have influenced this research study.

\section{References}

American Association of Colleges of Nursing. (2008). The Essentials of Baccalaureate Education FOR Professional Nursing Practice. Washigton, DC: Author.

Andrew, N., McGuinness, C., Reid, G., \& Corcoran, T. (2009). Greater than the sum of its parts: Transition into the first year of undergraduate nursing. Nursing Education Practice, 9, 13-21. https://doi.org/10.1016/j.nepr.2008.03.009

Barnett, T., Cross, M., Jacob, E., Shahwan-Akl, L., Welch, A., Caldwell, A., \& Berry, R. (2008). Building capacity for the clinical placement of nursing students. Collegian, 15(2), 55-61. https://doi.org/10.1016/j.colegn.2008.02.002

Barnsteiner, J. (2011). Teaching the Culture of Safety. Online Journal Issues Nurs., 16(3). Retrieved from www.medscape.com

Beech, I. (1999). Bracketing in Phenomenological Research. Nurse Researcher 6(3), 35-51. https://doi.org/10.7748/nr1999.04.6.3.35.c6086

Blum, C. A., Kamcuyan, J., \& Dean, A. (2012). Stakeholder Focus Groups to Inform Technology Based Strategy of Preceptor Support. Nursing Research and Practice. Canadian Nurses Association."Achieving excellence in professional practice: a guide to preceptorship and mentoring, 2004, www.cna-aiic.ca/.

Boyer, S. A. (2007). Competence and innovation in preceptor development: Updating our programs. Journal for Nurses in Professional Development, 24(2), E1-E6. https://doi.org/10.1097/01.NND.0000300872.43857.0b

Boyer, S. A. (2008). Competence and innovation in preceptor development: Updating our Programs. Journal for nurses in staff development, 24(2, E1-E6).

Broadbent, M., Moxham, L., Sander, T., Walker, S., \& Dwyer, T. (2014). Supporting Bachelor of nursing students within the clinical environment: perspectives of preceptors. Nurse Education Practice, 14(4), 403-409. https://doi.org/10.1016/j.nepr.2013.12.003

Budgen, C., \& Gamroth, L. (2008). An overview of practice education models. Nurse Education Today, 28(3), 273-283. https://doi.org/10.1016/j.nedt.2007.05.005

Carlson, E. (2013). Precepting and symbolic interactionism: A theoretical look at preceptorship during clinical practice. Journal of Advanced Nurse, 69, 457-464. https://doi.org/10.1111/j.1365-2648.2012.06047.x

Carper, B. (1978). Fundamental patterns of knowing in nursing. Advances in nursing science, 1, 13-23. https://doi.org/10.1097/00012272-197810000-00004

Charleston, R., \& Happell, B. (2005). Coping with uncertainty within the preceptorship experience: The perceptions of nursing students. Journal of Psychiatric Mental Health Nursing, 12, 303-309. https://doi.org/10.1111/j.1365-2850.2005.00837.x

Cohen, A. R., \& Bradford, D. L. (2005). Influence Model: Using Reciprocity and Exchange, to get what you need. Journal of ongoing excellence. John Wiley and Sons Inc. https://doi.org/10.1002/joe.20080

DeWolf, J. A., Perkin, C. A., Harrison, M. B., Laschinger, C., Oakley, P., Peterson, J. A., \& Seaton, F. (2010). Strategies to prepare and support preceptors and students for preceptorship. Nurse Education, 35(3), 98-100. https://doi.org/10.1097/NNE.0b013e3181d95014

Dimitriadou, A., Pizirtzidou, E., \& Lavdaniti, M. (2013). The concept of socialization in Nursing Education. International Journal of Caring Sciences, 6(3), 314-318.

Dinmohammadi, M., Peyrovi, H., \& Mehrdad, N. (2013). Concept analysis of Professional Socialization in Nursing. Nursing Forum, 48, 26-34. https://doi.org/10.1111/nuf.12006

Donley, R., Flaherty, M., Sarsfield, E., Burkhard, A., O'Brien, S., \& Anderson, K. (2014). Graduate clinical nurse preceptors: implications for improved intra-professional collaboration. OJIN: The Online Journal of Issues in Nursing, 19(3).

Duteau, J. (2012). Making a difference. The value of preceptorship programs in nursing education. Journal of continuing education 43, 37-43.

Franklin, N. F., Leathwick, S., \& Phillips, M. (2014). Clinical supervision at a magnet hospital: A review of the 
preceptor-facilitator model. Journal of Nursing Education and Practice, 4(1), 134-142.

Guba, E. G., \& Lincoln, Y. S. (1985). Naturalistic inquiry. London: Sage.

Hallen, K., \& Danielson (2009). Preceptoring nursing students: Registered nurses. Perceptions of nursing student preparation and study approaches in clinical. Nurse Education Today. Elsevier Ltd.

Hallet, C. (1995). Understanding the Phenomenological approach to Research. Nurse Researcher, 3(2), 55-65. https://doi.org/10.7748/nr.3.2.55.s6

Happell, B. (2009). A Model of Preceptorship in Nursing Reflecting the Complex Functions of the Role. Nursing Education Perspectives, 30(6).

Helminem, K., Tossavanien, K., \& Turunan, H. (2014). Assessing Clinical practice of student nurses: Views of teachers, Mentors and Students. Nurse Education Today, 34(8), 1161-1166. https://doi.org/10.1016/j.nedt.2014.04.007

Hilli, Y., Melendere, H. L., Salmu, M., \& Jonsen, E. (2014). Being a Preceptor. A Nordic Qualitative study. Nurse Educator Today. April 24 pii.SO260-6917 (14)00124-5 doi: 10.1016/j.nedt.

Horton, C. D., DePaoli, S., Hertach, M., \& Bower, M. (2012). Enhancing the effectiveness of nurse Preceptors. Journal Nurses Staff Development, 28(4), 1-7. https://doi.org/10.1097/NND.0b013e31825dfb90

Hurley, C., \& Snowden, S. (2008). Mentoring in times of Change. Nursing in Critical Care, 13(5), 269-275. https://doi.org/10.1111/j.1478-5153.2008.00293.x

Iwasiw, C. L., \& Goldberg, D. (1993). Peer teaching among nursing students in the clinical area: effects on student learning. Journal of Advanced Nursing, 18, 659-668. https://doi.org/10.1046/j.1365-2648.1993.18040659.x

Johnstone, C., \& Mohide, E. A. (2009). Addressing diversity in clinical nursing education: Support for preceptors. Nurse Education in Practice, 9, 340-347. https://doi.org/10.1016/j.nepr.2008.08.005

Jowett, R., \& McMullan, M. (2007). Learning in practice - practice educator role. Nurse Education in Practice, 7(4), 266-271. https://doi.org/10.1016/j.nepr.2006.08.008

Koloroutis, M. (2004). Relationship Based Care. A Model for Transforming Practice. Creative Healthcare Management. Minneapolis, Minnesota.

Kristan, H., \& Reed, W. (2013). Motivating the Unmotivated. Educational Theory and Practice. Edtheory. blogspot.com 2013/05.

Krueger, R. A. (1994). Focus Groups: A practical guide for applied research. California: Sage.

Lai, K. P., \& Lim, P. H. (2012). Concept of Professional Socialization in Nursing. IEJSME, 6(1), 31-35

Lee, T., Tzeng, W., Lin, C., \& Yeh, M. (2009). Effects of a Preceptorship program on turnover rate, cost, quality and professional development. Journal of Clinical Nursing, 18, 1217-1225. https://doi.org/10.1111/j.1365-2702.2008.02662.x

Lovering, S. (2012). The crescent of care: A nursing model to guide the care of Arab Muslim patients. Diversity and equality in health care, 9(3), 171.

Mallette, S. J., Loury, S., Engelke, M. K., \& Andrews, A. (2005). The integrative clinical preceptor model: a new method for teaching undergraduate community health nursing. Nurse Educator, 30(1), 21-26. https://doi.org/10.1097/00006223-200501000-00007

Matua, G. A. (2014). Challenges and Strategies for Building and maintaining effective Preceptor-Preceptee Relationships among Nurses. National Institutes of Health. Sultan Quboos, University Medical Journal, 14(4), 530-536.

Messersmith, A. (2008). Becoming a nurse: The role of communication in professional socialization. Unpublished $\mathrm{PhD}$ thesis) University of Kansas.

Monareng, L. V., Jooste, K., \& Dube, A. (2009). Preceptors and preceptees views on student nurses clinical accompaniment inBostwana. Africa Journal of Nursing and midwifery, 11(2), 113-127.

Moyer, B. A., \& Whitmann-Price, R. A. (2008). Nursing Education Foundation for practice excellence. F.A Davis Company: Philadelphia. Retrieved from www.fadavis.com

Myrick, F., Luhanga, F., Billay, D., Foley, V., \& Yonge, O. (2012). Putting the evidence into preceptor preparation. Nursing Research and Practice, 2012. 
Olsen, R. E., Klupp, N., \& Asteel-Burt, T. (2016). Re-imagining health professional socialization: an interactionist study of interprofessional education. Health Sociology Review. https://doi.org/10.1080/14461242.2015.1101702

O'Mara, L., McDonald,J., Gillepsie, M., Brown, H., \& Miles, L. (2014). Challenging Clinical Learning Environments: experience of undergraduate nursing students. Nurse Education Practice, 14(2), 208-2013. https://doi.org/10.1016/j.nepr.2013.08.012

Omer, Y. T., Suliman, W. A., \& Moola, S. (2015). Roles and Responsibilities of nurse preceptors: Perception of preceptors and preceptees. Nurse education in Practice.

Omer, Y. T., Suliman, W. A., Thomas, I., \& Joseph, (2013). Perception of nursing students to two models of preceptorship in clinical training. Nurse Educator in Practice, 13(3), 155-160. https://doi.org/10.1016/j.nepr.2013.02.003

Park, J. R., Warrad, H., Barker, J., \& Chapple, M. (2011). The knowledge and skills of pre-registration, masters and diploma qualified nurses: a preceptor perspective. Nurse Education, Practice, 11(1), 41-46. https://doi.org/10.1016/j.nepr.2010.06.004

Polit, D. F., \& Hungler, B. P. (1995). Nursing Research, Principles and methods (5th ed.). Philadelphia: J.B. Lippincott Company.

Price, A., \& Price, B. (2009). Role modeling practice with students on clinical placements. Nursing Standard, 24(11), 51-56. https://doi.org/10.7748/ns.24.11.51.s47

Rassool, G. H. (2000). The crescent and Islam: healing, nursing and the spiritual dimension. Some considerations towards an understanding of the Islamic perspectives on caring. Journal of Advanced Nursing, 32, 1476-1484 https://doi.org/10.1046/j.1365-2648.2000.01614.x

Reilly, A., \& Spratt, C. (2007). The perceptions of undergraduate student nurses of high fidelity simulation-based learning: A case report from the University of Tasmania. Nurse Education Today, 27, 542-550. https://doi.org/10.1016/j.nedt.2006.08.015

San Miguel, C., Rogan, F., Kilstoff, K., \& Brown, D. (2006). Clinically speaking: a communication skills program for students from non-English speaking backgrounds. Nurse Education in Practice, 6, 268-274. https://doi.org/10.1016/j.nepr.2006.02.004

Sedgwick, M., \& Yonge, O. (2008). We're it, 'we' re a team', 'we're family' means a sense of belonging. Rural remote Health. 8, 1021.

Sedgwick, M., \& Yonge, O. (2009). Students perception of faculty involvement in the rural hospital preceptorship experience. International Journal of Nursing Education Scholarship, $6(1)$. https://doi.org/10.2202/1548-923X.1833

Serra, M. N. (2008). Learning to be a nurse. Professional Identity in Nursing Students. Educational Sciences Journal, 5, 65-76.

Sherwood, G. (2011). Integrating quality and safety in nursing education and practice. Journal of Research in Nursing, 16, 226-239. https://doi.org/10.1177/1744987111400960

Shinyashiki, G. T., Mendez, I. A. C., Trevizan, A. M., \& Day, R. A. (2006). Rev. Latino-Am. Eufermagem

Taylor, B. (1995). Interpreting Phenomenology for nursing research. Nurse Researcher, 3(2), 66-79. https://doi.org/10.7748/nr.3.2.66.s7

The CCARE model of clinical supervision: bridging the theory to practice gap. Nurse Education in Practice 7(2), 103-111. https://doi.org/10.1016/j.nepr.2006.06.007

Thomas, C., Allen, R. L., \& Betram, E. (2012). The transition from student to new registered nurses in professional practice. Journal for nurses in staff development, 28(5), 243-249. https://doi.org/10.1097/NND.0b013e31826a009c

Udlis, K. A. (2008). Preceptorship in Undergraduate Nursing Education: An Integrative Review. Journal of nursing education, 47(1), 2-29. https://doi.org/10.3928/01484834-20080101-09

Van Leuven, K. A. (2014). Preparing the Next Generation of Nurse Practitioners. Journal for Nurse Practitioners, 10(4), 271-276. https://doi.org/10.1016/j.nurpra.2013.12.014

Wagner, A. L., \& Seymour, M. E. (2007). A model of Caring Mentorship for Nursing. Journal of Nursing Staff 
Development, 23(5), 201-2011. https://doi.org/10.1097/01.NND.0000294926.14296.49

Walker, S., Dwyer, T., Moxham, L., Boradbent, M., \& Sanders, T. (2013). Facilitators versus preceptor: which offers the best support to undergraduate nursing students? Nurse Education Today, 33(5), 530-535. https://doi.org/10.1016/j.nedt.2011.12.005

Wang, X. B., Ang, E., Fell, S., \& Gan, S. (2014). Preceptors' perceptions on benefits, rewards, supports and commitment to the preceptor role: A correlation quantitative research. International Journal of Evidence-Based healthcare, (12), 3. https://doi.org/10.1097/01.XEB.0000455193.17046.ec

Yonge, O., \& Myrick, F. (2005). Nursing Preceptorship: Connecting Practice and Education. Lippincot Williams and Wilkens, Philadelphia, Pa, USA.

\section{Copyrights}

Copyright for this article is retained by the author(s), with first publication rights granted to the journal.

This is an open-access article distributed under the terms and conditions of the Creative Commons Attribution license (http://creativecommons.org/licenses/by/4.0/). 